\title{
Science and technology policy and the National Innovation System in Argentina
}

\section{Daniel Chudnovsky}

Director of the Centre for Research for Change (CENIT)

and Professor of Economic Development in the

University of Buenos Aires.
This article looks at the strengths and weaknesses of the policies proposed in the Argentine National Multi-year Science and Technology Plan, 1998-2000, within the conceptual framework of the National Innovation System (NIS) approach. In the light of a severe diagnosis of the weaknesses of Argentine efforts in this field, the new public policies are designed to promote the interaction of the many agents and institutions involved in those efforts, to change the rules governing the allocation of public resources to research, to promote strategic plans and evaluation mechanisms in public bodies in this field, and to induce greater voluntary spending by the private sector through fiscal credits for technological research and development and a Technological Advisers Programme, in order to give better attention to the demands of small and medium-sized enterprises. However, there are very profound and severe shortcomings in the ability of the Argentine financial system to provide finance for longterm investments in intangible assets, in the capacity of the educational system to link up with the needs of the production sector, and in the ability of the scientific institutions to interact with the educational system and the production sector. Although these shortcomings are mentioned in the Plan, they are not given the amount of attention needed to begin to reverse them. The long and frustrating past history of science and technology policies in the country, which have registered more failures than successes, and the partial success of the laissez-faire policy applied in the 1990s, which was considered to be a good policy by most of domestic and foreign big business, militate against the success of the initiatives under way. At the same time, and in spite of its stimulating suggestions, the approach taken by the NIS reflects serious ambiguities in its normative and conceptual aspects which limit its practical applicability. 


\section{I}

\section{Introduction}

In December 1997, the government Science and Technology Cabinet (GACTEC) approved the National Multi-year Science and Technology Plan 1998-2000 (Argentina, GACTEC, 1997), hereinafter referred to as the Plan, whose central objective is no less than "the development and strengthening of the national science, technology and innovation system" (Argentina, GACTEC, 1997). This was the first time in Argentina that the National Innovation System (NIS) approach was put forward at the official level, and the fact that a science and technology plan was prepared was also almost a novelty. ${ }^{1}$

The Plan was the result of a series of institutional changes initiated in July 1996, when the Department of Science and Technology was once again brought under the Ministry of Culture and Education and the reorganization of the science and technology sector was begun.

After an intensive debate which was reflected in the document entitled "Bases for the discussion of a science and technology policy", prepared by a hundred or so experts, at the end of the year GACTEC was set up, to be chaired by the Head of the Cabinet of Ministers and made up of the Ministers of the economy, education, health, foreign relations and defence, and natural resources and sustainable development. The Department of Science and Technology acts as the executive secretariat of GACTEC.

The National Agency for the Promotion of Science and Technology (hereinafter called "the Agency") was also set up at the end of 1996, to be responsible exclusively for financing non-profit-making research projects in the public and private sector and promot-

$\square$ This is a revised version of the study prepared for the OASMCT (Brazil) project "Globalization and local innovation: Case studies of local systems within MERCOSUR and proposals for science and technology policies". The author wishes to thank Juan Carlos Del Bello and Jorge Katz for their comments on a preliminary version, without of course associating them in any way with the views expressed herein. The data used were those available at the beginning of 1998; the National Multi-year Science and Technology Plan 1999-2001, which is due to appear shortly, will provide updated data and policy descriptions.

1 The only precedent goes back to 1971, when the Secretariat of the National Council for Science and Technology prepared a National Science and Technology Plan, 1971-1975. ing technological innovation in the private sector. In October 1997, GACTEC prepared the Plan, which was submitted along with the draft national budget for 1998 and simultaneously thrown open for public discussion.

This dynamism is in sharp contrast with the laissez-faire with regard to technology policy (and also to some extent scientific policy) displayed not only by the Menem government up to 1996 but also by the preceding Argentine governments, both civil and military (for details of the situation in this respect in the 1960s and 1970s, see Adler, 1987). ${ }^{2}$

Whereas up to 1990 laissez-faire was practiced fundamentally by omission and in macroeconomic situations which were not very favourable to growth, we argued in a previous paper that under the present administration laissez-faire has been applied as part of orthodox economic theory, as a mainstream economic approach (Chudnovsky and López, 1995). Such theory considers science and technology basically as exogenous variables ${ }^{3}$ and, in general, adheres to the policy recommendations of the so-called Washington Consensus (Williamson, 1990), which gives priority to trade liberalization, privatization of public enterprises and the promotion of foreign direct investment (FDI) as the fundamental instruments for securing the technological modernization of developing countries.

According to the mainstream economic approach, opening up the economy to imports would stimulate an improvement in the efficiency of the

\footnotetext{
2 The most outstanding exceptions to this historical trend were in the second half of the 1950s, when the authorities of the time set up the National Atomic Energy Commission (CNEA), the National Institute of Agricultural Technology (INTA), the National Institute of Industrial Technology (INTI), and the National Council for Scientific and Technological Research (CONICET); in the period between 1969 and 1975, when the National Council for Science and Technology was set up and laws were adopted on the transfer of technology; and to a much smaller extent in 19841989, when a policy on informatics was proposed and the Office for the Transfer of Technology was set up in CONICET, together with some other initiatives (Chudnovsky and López, 1995).

${ }^{3}$ Only in recent years has technological change begun to be incorporated as an endogenous variable in economic growth models (e.g., in the works of Paul Romer).
} 
productive sector through the greater competition on the local market, while at the same time it would facilitate access to the latest machinery and equipment, whose importation was favoured by the zero tariff in force until a little while ago in Argentina. The privatization of public enterprises would not only make them more efficient in the provision of goods and services but also, through the elimination of the "Buy National" clauses, it would give rise to greater competition among their own suppliers.

Liberalization of the rules on FDI, for its part, would promote the incorporation and dissemination of the technical and management know-how of foreign investors. The deregulation of technology transfer agreements would be a further stimulus for the technological modernization process.

Among the various policies adopted by the present administration, these policies have undoubtedly been those which have had the greatest impact on the technological modernization of the country. In an economy with stable prices and a rapid growth rate, a big increase in imports of capital goods and FDI inflows, together with the substantial rise in the productivity of labour in the 1990s, would appear to bear witness to the success of the policies applied.

However, the fact that a large part of the production apparatus has had great difficulty in coming closer to international best technological practices and that, in spite of the increase in expenditure on science and technology in the $1990 \mathrm{~s},{ }^{4}$ the crisis in the public institutions responsible for these activities prevents them from defining their objectives and research priorities as a function of the economic and social demands of the country, reflects the marginal role of endogenous scientific and technological efforts in the current policies.

The growing spread of non-orthodox theoretical approaches among those responsible for defining technology policy in the member countries of the Organization for Economic Cooperation and Development (OECD) has created a favourable setting for the adoption of views on the problems of technological modernization and policies for furthering it which are considerably different from those advocated in the mainstream economic approach and the Washington Consensus. $^{5}$

\footnotetext{
${ }^{4}$ Expenditure on science and technology, as a percentage of GDP, went up from around $0.33 \%$ in $1985-1990$ to $0.40 \%$ in 1994 and $0.46 \%$ in 1996 (Argentina, GACTEC, 1997).

${ }^{5}$ Although Williamson (1997) has modified some of the original recommendations of the Washington Consensus, especially with
}

Since, in the case of the complex phenomena of the acquisition, adaptation and development of technology, markets either do not exist or suffer from serious faults, the transmission of information and knowledge is imperfect and enterprises act with only limited rationality. Public policies have an important role to play in this field, especially with respect to small and medium-sized enterprises (SMEs), which are those that have the greatest difficulty in adapting to the new competition conditions.

Furthermore, while the importation of machinery and equipment and the inflow of FDI facilitate technological modernization and the codifiable aspects of technological know-how give rise to commercial transactions, this process also generates a series of positive externalities and synergies which are not expressed through the market and may require coordination and promotion agencies at the national and local government level, which obviously means abandoning the principle of laissez-faire.

This view of the problem had already been promoted by some officials of the present government through isolated initiatives such as Law No. 23877 on the Promotion and Development of Technological Innovation, adopted in 1990 and provided with the corresponding regulatory mechanism in 1992, and the Technological Modernization Programme, co-financed with the Inter-American Development Bank, which came into effect in 1994. With the recent institutional changes and the application of the National Science and Technology Plan ("the Plan"), official status has been given to an active and, in principle, much better coordinated policy in this field.

The dynamic approach recently displayed by the government in this field is undoubtedly a promising development, because it seeks to make a start on reversing the profound crisis suffered by the main public institutions and bodies responsible for science and technology and to stimulate the private sector to make a bigger effort in this area. In view of this, the present article aims to analyse the main policies proposed in the Plan and to identify their strengths and weaknesses from the standpoint of the conceptual framework provided by the National Innovation System approach.

regard to exchange-rate policy and the way trade liberalization should be carried out, the problems of technology policy are not dealt with in the new recommendations. 


\section{II}

\section{The conceptual framework}

In the mainstream approach, intangible technology is seen as a code of knowledge generated by the research and development (R\&D) departments of specialized firms. To a greater or lesser extent, these departments make use of the scientific knowledge generated in the universities and public R\&D institutes.

According to the logic of the linear approach to science and technology policy (OECD, 1992), which is inspired in part by mainstream economics, the results of public-sector R\&D efforts spill down to users as public goods. In private enterprises, innovative efforts are generated in their R\&D departments, from which they spread internally to the production and marketing departments and reach the market in the form of product and process innovations.

To the extent that knowledge is codified, its users can reproduce the respective instructions without much difficulty. Technology would therefore be an exogenous factor for most enterprises. If it were privately owned, through patents or other mechanisms, they could acquire it in the market by paying royalties or other compensations. If it were freely available, they would simply obtain it as technical information.

In these types of approaches, the main objectives of science and technology policy are to ensure a continuous flow of innovations -through adequate State finance for the scientific and technological research carried on in universities and public laboratories, protection for intellectual property, and fiscal incentives for R\&D expenditure by the private sector- and to favour the dissemination of innovations throughout the system of production by means of an efficient information system, directed mainly at the SMEs. Monopolistic conduct that might arise in the use of intangible assets would be offset by policies designed to protect competition.

In contrast with the approach taken by mainstream economics, evolutionary or neo-Schumpeterian theories consider that scientific and technological knowledge is not perfectly codifiable, so that its transferability is not perfect. Both the generation and the use of knowledge require an endogenous effort based on the accumulation of scientific, technical and organizational capacities, which gives rise to increases in productivity and efficiency and, ultimately, the generation of a growing flow of innovations with regard to products and production processes.

The notion of technological capacities tries to cover the wide range of knowledge and skills needed in order to purchase, assimilate, use, adapt, change and create technologies. This concept goes beyond the traditional notions of engineering and technical know-how, to include knowledge of both organizational procedures and structures and of patterns of behaviour (of workers or clients, for example). Firms need certain supplementary assets in order to create, mobilize and improve their technological capacities, including such assets as organizational flexibility, financial resources, quality of human resources, and sophisticated support and information services (OECD, 1992).

The process of acquiring the scientific, technical and organizational knowledge needed in order to use the available technologies efficiently is long, risky and unpredictable. It involves the development of technological and organizational capacities through deliberate efforts of learning in the production process ("learning by doing"), in marketing and contacts with clients ("learning by using") and in an ongoing search for new technical solutions in R\&D units or in less formal places such as technical offices ("learning by searching"). In addition to major in-house efforts, this process involves interacting with suppliers of equipment, parts and components, with licensors, with foreign partners, with technological institutes and universities, and with clients ("learning by interacting"). It is a collective learning process in which, although the epicentre consists of the manufacturing enterprises themselves and the various sectors in which they operate, other public and private actors and institutions are also involved.

The tacit, localized and accumulative nature of technological knowledge, the emphasis on the learning process and the various sources underlying it, and the importance of feedback and of the numerous interactions which characterize and induce it, all go to make 
up a complex and constantly changing social setting which is completely different from the simplified scheme which the mainstream economic literature uses to address these issues.

The numerous actors and institutions participating in the innovation process and the importance of their interaction in order to achieve a form of innovation which bears fruit in terms of private and social benefits have been effectively described in the neo-Schumpeterian literature through the concept of the national innovation system.

The first definition of this system, suggested by Freeman (1988), identified it with the network of public and private institutions whose activities and interactions initiate, import, modify and disseminate new technologies. In a subsequent study, Freeman says that List was the first author to use that approach, although he gave it a different name (Freeman, 1995). In the studies by Lundvall (1992), by Nelson (ed., 1993) and by Edquist (ed., 1997), the NIS is analysed from various angles and on the basis of various different national experiences. At the same time, the concept of the NIS has gradually been spreading from the academic world to the world of policy-makers, and it is being used in one form or another both in OECD documents (OECD, 1992 and $1996 \mathrm{~b})$ and in those of a number of OECD member countries.

In Edquist (1997) there is an excellent study of the approach based on the NIS. In our opinion, Edquist's study is right in considering that this is not a formal theory but rather a conceptual framework for addressing the issues in question from a holistic, interdisciplinary and historical (albeit conceptually vague) standpoint.

To put it briefly, the main point in an approach based on the NIS is that it considers innovation and learning as crucial aspects. Although enterprises are the backbone of the NIS, they do not innovate alone. Innovation is an interactive process, and in the final analysis the approach stresses above all the importance of the interactions among the various different actors and institutions that participate in the complex collective process. Unlike the linear model, which placed emphasis essentially on the generation of innovations, the NIS approach places just as much or even more stress on their dissemination.

Although different authors have somewhat differing views in this respect, the approaches based on the NIS refer to greater or lesser innovations in prod- ucts, processes and forms of organization. Furthermore, they do not only deal with innovations in the countries that are on the leading edge of technology but also in those following a strategy of trying to catch up and keep up with the most advanced economies (Mytelka, 1996).

At the same time, these approaches try to get away from the usual dichotomy of addressing the problem in the light of only two fundamental institutions -the market and the State- and they also take into account, among many other elements, universities, banks, intellectual property legislation, and technological research and services institutes.

Apart from the enormous difficulties involved in trying to identify and quantify the various indicators (in addition to R\&D expenditure and the number of patents taken out) that would give an idea of the level of performance of an NIS, the weakest points in this approach are connected with the relative weight of inputs imported from abroad compared with endogenous efforts to absorb6 and generate innovations, and, above all, with its normative aspects as regards the role of public policies in forming NISs.

In a globalized economy where FDI grows faster than international trade and the costs of the transmission of information and transport are continually going down, external flows of technological knowledge take on growing importance. In so far as the knowledge generated in processes of innovation is tacit, accumulative and localized, however, there is a good deal of room at the national and local level for the development of endogenous technological capability. Indeed, such capability is indispensable in order, at the very least, to be able to efficiently absorb the knowledge coming from the exterior and, obviously, to be able to adapt, modify and generate new knowledge.

In spite of the growing interdependence of the industrialized countries as regards flows of investment and technology, the pilot studies on NISs carried out in a number of OECD countries clearly indicate that in those countries enterprises base their innovation process essentially on their own R\&D efforts and make relatively little use of imported flows (OECD, 1996a).

\footnotetext{
6 This fundamental issue is ignored in the study by Edquist (1997). In the footnote on page 44 of that study, however, the author notes that in all countries except the economically largest ones, this dissemination (of technology) mainly represents absorption from the exterior. This is the case in Sweden as well as in Mexico and India.
} 
In contrast, most of the developing countries generally display the opposite situation. Not only are the resources allocated to $R \& D$ by the private sector relatively scanty, but enterprises interact much more with suppliers of technology from abroad than with local firms or institutions. Furthermore, the links are generally in only one direction (licenses, franchises, subcontracting) and there are few two-way agreements regarding $\mathrm{R} \& \mathrm{D}$, production or marketing (following the classification proposed by Mytelka, 1992).

Moreover, in the case of the Asian countries which have successfully followed strategies aimed at catching up with the most advanced countries in this respect it may be noted that although efforts to absorb technologies from abroad have been a generalized feature of their industrialization strategies, the channels used have differed considerably from one country to another, as have the industrial sectors selected in the different stages of their strategies (Mowery, 1993; Lall, 1992).

The opinions of different authors regarding the role of public policies in the formation of NISs vary considerably. Whereas Nelson and Rosenberg consider that NISs evolve spontaneously and are thus not designed in a deliberate manner, other authors maintain that the State has an important role to play in their formation. Edquist's position seems the most plausible: some elements of the NIS do evolve spontaneously, but others are the subject of deliberate public policies. This author also considers that the NIS approach is useful for policy formulation in so far as it provides an analytical framework for the identification of specific policy issues which is different from that resulting from the application of orthodox economics.

However, the NIS approach does not generate very precise normative elements for policy formulation. Authors like Nelson and Dahlman would appear to be basically in agreement with the recommendations of the Washington Consensus regarding the positive role of FDI and trade openness, though they supplement them with horizontal policies designed to increase technological capability and the capacity for the social absorption of knowledge (Dahlman and Nelson, 1993). In contrast, other authors such as Freeman and, above all, Lall seem to assign much more importance to selective policies on industrial and technological matters (Lall, 1995).

With regard to the late-industrializing countries, there can be no doubt that first of all the experience of Japan and later that of the "Asian Tigers" has been a source of inspiration on what relatively successful NISs should be like. Although this inspiration is clearly visible in the works of Freeman (1988 and 1995) and Lall (1992 and 1995), however, it is much less evident in the studies by Nelson.

As noted by David and Foray (1995), from the social point of view it is important that an NIS should have "distributive power" in order to facilitate the efficient distribution and use of the scientific and technological knowledge available in society. This view assumes that the same means used to ensure greater private profitability of innovative activities may reduce the distributive power of the NIS. Consequently, there may be a conflict between "appropriability", which would favour greater accumulation of new knowledge, and "distributive power", which would help to ensure that such knowledge was more socially "useful".

Hence, in the case of the industrialized countries, the OECD has rightly noted that the dilemma for public policies is that they have to reconcile two main objectives. On the one hand, they must develop an environment with abundant incentives, so that the expected private benefits are substantial and motivate enterprises to generate increasing amounts of innovations. These incentives should not only consist of tax deductions for R\&D expenditure and protection of intellectual property but should also extend to the financing of pre-competitive research, the promotion of strategic alliances, and public sector purchases, among other aspects.

On the other hand, public policies must promote numerous spillover effects, so that firms only appropriate a part of the benefits of innovation and its social profitability is maximized. This involves a number of actions including not only the defence of competition but also measures to promote linkages among enterprises and between enterprises, universities and research institutes at the regional level; the provision of advisory and consultancy services for SMEs; the operation of enterprise brooders, and training and retraining programmes for technical and management staff (OECD, 1992 and 1997).

To sum up, although the NIS approach is conceptually vague, it is undoubtedly useful for addressing and analysing the problems of innovation in developed and developing countries. It identifies the most important agents and institutions that must be taken into account when forming NISs, and it is flexible enough to adapt 
to the various different historical and institutional situations. Although it does suggest the areas where public policies should act and generally rejects the idea of laissez-faire, however, it does not make any specific recommendations about the policies that should be followed.

\section{III}

\section{The new science and technology policies in Argentina}

\section{The diagnosis}

Although it does not go into the underlying causes, the Plan makes a searching diagnosis of the Argentine situation with regard to science and technology. In general terms, we agree with this diagnosis, which is summarized below.

First, the noteworthy recent growth of the Argentine economy (almost 6\% per year on average between 1990 and 1996) and of labour productivity (47\% between 1990 and 1996) $)^{7}$ has been based on machinery, inputs and knowledge mainly brought in from the exterior. The data on imports of capital goods, foreign direct investment and patents clearly illustrate this.

Imports of machinery and equipment increased from US\$635 million to US\$6037 million between 1990 and 1994, went down by $20 \%$ in 1995, but registered an upward trend again in 1996 and 1997. ${ }^{8}$ FDI flows increased from an annual average of US\$2.7 billion in 1990-1993, when they corresponded mainly to the acquisition of State enterprises, to US\$3.8 billion in 1994-1996, when industry, mining and some services were the main recipients. Patent applications submitted in Argentina by non-residents increased from

\footnotetext{
${ }^{7}$ According to official information, labour productivity in industry grew by $58 \%$ (6.8\% per year) between 1990 and the first half of 1997 , whereas in the 1980s it grew by an average of only $0.8 \%$ per year (CEP, 1997).

${ }^{8}$ Gross fixed domestic investment increased from $13.4 \%$ to 23.6\% of GDP between 1990 and 1994. The investment coefficient went down to $20.7 \%$ in 1995 but recovered in 1996 $(21.5 \%)$ and is estimated to have amounted to $25 \%$ of GDP in 1997. Within this investment, the share of imported capital goods increased from 13\% in the first quarter of 1991 to $40 \%$ in the first quarter of 1997, while the share of domestic capital goods went down from $20 \%$ to $12 \%$ over the same period (Argentina, Ministry of the Economy and Public Works and Services, Economic Policy Department, 1997).
}

1955 in 1990 to 4012 in 1996. After having amounted to over 1000 per year in the 1980s and over 900 per year in the early 1990s, patent applications by residents went down to less than 700 in 1994 and 1995, recovering to 1097 in 1996. Argentine residents take out hardly any patents abroad.

Consequently, it is noted in the Plan that the significant economic growth process in the 1990s has generated few opportunities for making use of the country's stock of human resources. It has left out a large part of the SMEs, which have displayed serious difficulties in adapting to the new rules of the Argentine economy, and it has not generated sufficient incentives for the big firms to make systematic research, development and innovation efforts.

As may be seen from table 1, private-sector expenditure on science and technology is completely out of line with international levels. It is estimated at $0.13 \%$ of GDP, which is far below the levels not only of the industrialized countries (over 1\%) but even of Chile and Brazil (0.27\% and $0.18 \%$, respectively).

Although a large part of the inputs for product and process innovation come from abroad, it may be assumed that the more intensive competition registered in the Argentine economy in recent years is giving rise to sizeable endogenous innovation activities and technological efforts to absorb and adapt this knowledge. Thus, it is estimated that, altogether, companies have increased their R\&D expenditure, in constant 1996 pesos, from 214 million in 1993 to 369 million in 1996 (i.e., from $0.08 \%$ to $0.13 \%$ of GDP). ${ }^{9}$

\footnotetext{
${ }^{9}$ As it may be assumed that this estimate does not take into account all the innovation efforts which are probably being made in most large foreign-owned and national firms and in small and medium-sized enterprises, the Department of Science and Technology is carrying out a survey on the technological conduct of Argentine industrial enterprises, through the National Institute of Statistics and Censuses (INDEC).
} 
TABLE 1

International comparison of investment in science and technology ${ }^{\text {a }}$

\begin{tabular}{|c|c|c|c|c|c|c|}
\hline \multirow{2}{*}{ Country } & \multicolumn{2}{|c|}{$\begin{array}{l}\text { Total investment in } \\
\text { science and technology }\end{array}$} & \multicolumn{2}{|c|}{ Government and others ${ }^{b}$} & \multicolumn{2}{|c|}{ Enterprises } \\
\hline & $\begin{array}{l}\text { Millions } \\
\text { of US\$ }\end{array}$ & $\%$ of GDP & $\begin{array}{l}\text { Millions } \\
\text { of US\$ }\end{array}$ & $\%$ of GDP & $\begin{array}{l}\text { Millions } \\
\text { of US\$ }\end{array}$ & $\%$ of GDP \\
\hline United States & 184300 & 2.48 & 66822 & 0.87 & 117478 & 1.53 \\
\hline Japan & 76004 & 2.78 & 22573 & 0.82 & 53431 & 1.96 \\
\hline Germany & 37149 & 2.48 & 14785 & 0.99 & 22363 & 1.49 \\
\hline France & 26721 & 2.38 & 11788 & 1.05 & 14933 & 1.33 \\
\hline South Korea & 12200 & 2.69 & 3282 & 0.72 & 8918 & 1.97 \\
\hline Spain & 4376 & 0.92 & 2464 & 0.52 & 1912 & 0.40 \\
\hline Brazil $^{\mathrm{c}}$ & 5888 & 0.87 & 4107 & 0.61 & 1850 & 0.27 \\
\hline Mexico $^{c}$ & 1114 & 0.33 & 1039 & 0.31 & 75 & 0.02 \\
\hline Argentina ${ }^{c}$ & 1353 & 0.46 & 984 & 0.33 & 369 & 0.13 \\
\hline Chile $^{\mathrm{c}}$ & 398 & 0.78 & 310 & 0.60 & 88 & 0.18 \\
\hline
\end{tabular}

Source: Argentina, GACTEC (1997).

${ }^{a}$ Last available year.

${ }^{\mathrm{b}}$ Includes non-profit-making institutions and private higher education.

${ }^{\mathrm{c}}$ Corresponds to total expenditure on science and technology, which covers more than expenditure on research and development.

At all events, regardless of the actual size of the corresponding investment, the Plan rightly notes that the private sector efforts are generally of a short-term nature, do not include systematic scientific and technological research activities, are not linked up with public science and technology institutions, and are not carried out in networks with active participation of suppliers, users and clients. In short, they are far from having the scale required in order to tackle the challenges involved in the formation of an NIS.

Second, Argentina is at a clear disadvantage compared with the industrialized countries and South Korea, though it is relatively better off than Mexico, Brazil and Chile in terms of the proportion of researchers in relation to the economically active population (table 2). In contrast with what occurs in the industrialized countries and South Korea, almost all the research personnel work in national public sector bodies, including CONICET, and in national universities.

Although Argentina has highly-trained human resources and some of its scientific researchers and research groups have won worldwide recognition for their contributions (Argentina is the only country in the region which has several Nobel science prizewinners), it is impossible to overlook the ageing of the research staff and the scanty relative development of many scientific disciplines. As may be seen from table 2, the productivity of scientific research, as measured by the number of papers published in international reviews, is not very high compared with the industrialized countries. ${ }^{10}$ Nevertheless, it is higher than that of a number of developing countries, including South Korea. At the same time, there has been a disturbing relative decline in the number of students studying fundamental and applied science (from 40\% in 1986 to $33 \%$ in 1996).

Furthermore, the interaction of the educational sector with the scientific and technological sectors and above all with the production sector is still very limited. Teaching has few links with research, and the research efforts in the universities have few links with each other and with the needs of the production sectors.

Third, public sector expenditure on science and technology represented only $0.33 \%$ of GDP in 1996, which is very little by international standards (see table 1). Moreover, it is estimated that in 1996 fundamental research accounted for $28 \%$ of this total, applied research for 50\% and experimental development for $22 \%$. This structure is very different from that of the industrialized countries, where experimental development accounts for about two-thirds of the total and fundamental and applied research account

\footnotetext{
${ }^{10}$ It is hard to determine from the available information whether the productivity of scientific research in Argentina is rather low because of the scarcity or faulty allocation of funds or because a number of the researchers shown in the records are not actually engaged in research.
} 
TABLE 2

Number of researchers in science and technology

and papers published in international reviews ${ }^{a}$

\begin{tabular}{|c|c|c|c|c|c|}
\hline Country & $\begin{array}{l}\text { Number of } \\
\text { researchers }\end{array}$ & $\begin{array}{c}\text { Researchers/ } \\
\text { EAP }\end{array}$ & $\begin{array}{c}\text { Number of } \\
\text { papers published } \\
\text { (annual average } \\
1992-1995)\end{array}$ & $\begin{array}{l}\text { Number of } \\
\text { papers per } \\
\text { researcher }\end{array}$ & $\begin{array}{c}\text { Number of } \\
\text { papers published/ } \\
\text { EAP } b\end{array}$ \\
\hline United States & 962700 & 7.4 & 253347 & 0.26 & 20.27 \\
\hline United Kingdom & 140000 & 5.0 & 51840 & 0.37 & 18.51 \\
\hline Germany & 240802 & 5.7 & 47036 & 0.20 & 11.20 \\
\hline France & 129780 & 4.9 & 37107 & 0.29 & 14.27 \\
\hline Spain & 41681 & 2.8 & 13698 & 0.33 & 9.13 \\
\hline Argentina & 22147 & 1.9 & 2306 & 0.11 & 1.92 \\
\hline Brazil & 37300 & 0.7 & 4415 & 0.12 & 0.75 \\
\hline Mexico & 19434 & 0.6 & 2254 & 0.16 & 0.68 \\
\hline Chile & 6429 & 1.3 & 1228 & 0.19 & 2.46 \\
\hline South Korea & 98764 & 4.9 & 1108 & 0.01 & 0.55 \\
\hline
\end{tabular}

Source: Argentina, GACTEC (1997).

${ }^{a}$ Last available year.

${ }^{\mathrm{b}}$ Per 100000 members of the economically active population (EAP).

for relatively much smaller proportions than in Argentina.

Finally, in the public sector bodies there is a lack of priorities, serious shortcomings in management, lack of coordination and of quality evaluation mechanisms, and serious imbalances in budgetary allocation. Thus, $72 \%$ of the national budget in this area is concentrated in four institutions: the national universities, CONICET, the National Institute of Agroindustrial Technology (INTA), and the National Atomic Energy Commission (CNEA). The weight of the latter institution in the national budget is a clear reflection of the high priority given to nuclear energy in the past. In contrast, although the manufacturing sector generates $25 \%$ of GDP, the National Institute of Industrial Technology (INTI) receives less than 5\% of the national science and technology budget. Furthermore, in a federal country like Argentina the provinces receive practically no share of the public finance for scientific and technological activities.

Although the evaluation of public sector activities in this field is a task which has only recently been begun, it is known that most of the activities carried out at present are of a short-term nature, even though there are institutions which have shown that they are capable of carrying out long-term scientific and technological development projects. Lack of coordination among the programmes of the different organizations, lack of precise objectives and evaluation mechanisms, and concentration on the provision of routine services and technical assistance are the most notable features of public sector scientific and technological activities.

It is evident that the science and technology effort of the public sector -and even more so that of private firms- is not only clearly insufficient but is also uncoordinated, is mostly not designed to meet the needs of the production sector in general and the SMEs in particular, and does not generate the synergies called for in the NIS approach.

When trying to understand how and why the present situation has been reached, it is necessary to take into account the long and complicated prior history of the scientific and technological institutions, the characteristics assumed by the industrialization process, the role played in it by public and private enterprises and the scientific community itself, and also the actions of the Argentine State, but this task is outside the scope of the present article. ${ }^{11}$ The main responsibility belongs to the national government, however, and we will therefore deal primarily with recent institutional changes and with the policies adopted in order to begin to change the situation identified in the diagnosis.

\section{Recent institutional changes}

In the course of its history, the Department of Science and Technology has come under various higher bodies, most frequently the Office of the President of

${ }^{11}$ For an analysis of this matter, see Chudnovsky and López (1995). 
the Nation and the Ministry of Education. However, it was never able to effectively fulfill the coordination and planning function originally assigned to it. Consequently, the science and technology institutions have generally been left to their own devices or to the logic of the sector with which they were most closely related.

As from July 1996, the Department has formed part of the Ministry of Culture and Education. ${ }^{12}$ Its political function and its coordination and planning functions have taken on greater importance since the establishment of GACTEC as a mechanism for dealing with scientific and technological issues in the most important ministries, and because of its responsibility in the formulation of the Plan. An Inter-agency Action Commission has also been set up, made up of all the national public sector science and technology bodies (except the universities).

In addition, in order to involve the provinces in the setting of regional priorities, the Federal Council for Science and Technology (COFECYT) has been established, chaired by the Secretary for Science and Technology and made up of the top officials responsible for these matters in the 23 provinces and the city of Buenos Aires.

Unlike the United States and various Latin American countries, in Argentina there was no institution responsible exclusively for the promotion and development of scientific research and/or technological development, since CONICET is an executive agency which also carries out functions of promotion and development. Consequently, it was decided to set up the National Agency for the Promotion of Science and Technology.

As well as strengthening the promotion machinery and making it accessible to all research groups, regardless of the institution they belong to, the establishment of the Agency is designed to reorganize and improve the coordination of the existing instruments. For this purpose, it has two funds: FONCYT and FONTAR.

FONCYT subsidizes the following activities through public competitions: i) scientific and technological research projects (costing up to 25000 pesos per year) carried out by groups of researchers working in public or private non-profit-making institu-

12 In addition to CONICET, the National Atomic Energy Commission also comes under the Department of Science and Technology. tions; the results of these projects are to be published a priori in open-circulation reviews; ii) research and development projects whose results are a priori public goods but may be subject to conditions of confidentiality for commercial reasons, with the sponsor having priority for their acquisition; these projects (which may cost up to 1200000 pesos) are concerted between the enterprise involved and the non-profit-making institution carrying out the research and must receive financing from the sponsor.

FONTAR finances technological innovation and modernization projects whose results are appropriable and are designed to improve the competitiveness of enterprises producing goods or services. This fund brings together the various instruments for this purpose which were previously dispersed, such as Law No. 23877 and the IDB Technological Modernization Programme. The clients of FONTAR are innovative enterprises and also non-profit-making institutions wishing to obtain better equipment in order to improve their capacity to provide technical assistance to the private sector.

The conception, formulation and public discussion of the Plan represent an important institutional change. The Plan is basically a programme of work marked by its flexibility, which allows it to incorporate new policy initiatives each year, and by its multidimensional nature, since it covers both horizontal policies and sectoral, regional and thematic policies.

In view of the lack of coordination and planning of science and technology efforts and the conflicts of interest which may arise in institutions that are responsible both for executing projects and for promoting research, these changes not only involve a healthy dose of common sense but are also in keeping with the direction suggested by the NIS approach. Naturally, their virtues or defects will only be revealed in the course of their practical execution, through the policy measures indicated in the Plan.

\section{The main policy measures and their effects on the public sector}

In order to begin to reverse the situation described earlier, the Plan proposes that the national effort in the field of science, technology and innovation should be improved, augmented and made more efficient by promoting a greater effort on the part of the private sector and the provinces through the co-financing of projects by private enterprises and the provincial authorities. 
Instead of concentrating almost exclusively on supply, as has traditionally been the case, the policies proposed in the Plan aim to guide national and regional efforts in the area of science, technology and innovation as a function of the demands of the production sector and the social and regional needs of the country. At the same time, they are inspired by the NIS approach and seek to promote better coordination and linkages among the public and private sector actors and institutions taking part in the process of generating, disseminating and absorbing knowledge and innovations.

The Plan is much more specific with regard to horizontal policies than with respect to thematic, sectoral and regional policies, so we will concentrate on the first-named. In this section we will refer to those that fundamentally concern the public sector, while in the following section we will deal with those that seek to promote a process of innovation in the private sector.

At all events, some comments are called for regarding sectoral, regional and thematic problems. As the demand for science, technology and innovation stems from the demand for the economic and social goods and services that incorporate these factors, this should be a central element of sectoral policies, as the Plan document rightly asserts.

Whereas correct diagnoses have been made and some appropriate policy measures have been outlined in such activities as food and agriculture and mining, this is far from having occurred in such important sectors as the rest of manufacturing, the environment, education and health. In this respect, the unequal degree of preparation of sectoral priorities in the Plan is a reflection of the levels of interest displayed by the respective responsible authorities in the execution of the task and, to a certain extent, the effectiveness of GACTEC as a coordination and planning mechanism.

$\mathrm{Be}$ that as it may, it is worth bearing in mind that, unlike what happened in the past, in the 1990s the national government has shown little propensity to formulate and implement sectoral policies, the most noteworthy exceptions to this in the production sector being the motor industry, mining and the Spatial Organization Plan (although the latter is an activity rather than a sector).

At the level of the regions, the Plan incorporates the results of a Pilot Programme for the Identification of Needs with regard to scientific and technological applications and knowledge, although these results are far from constituting policy guidelines for guiding the efforts of the provinces in the field of science and technology and much less for forming regional innovation systems.

Biotechnology and studies on the Argentine marine environment are the only two thematic areas dealt with in the Plan. In the first of these areas, research priorities are proposed and some activities are suggested, such as the implementation of a system for evaluating biotechnology projects and promoting microenterprises and small-scale enterprises through a system of enterprise brooders. In the second, priorities are suggested for allocating the funds of the Agency.

Although, among the horizontal policies proposed in the Plan, some measures are suggested for securing better access to information from satellites and the Internet, no policies are proposed for the promotion of endogenous efforts in the areas of microelectronics, informatics, telecommunications, or new materials: generic technologies which are abundantly referred to in most of the official documents on science and technology in both industrialized and developing countries. In the 1999-2001 Plan, it has been decided to place emphasis on the field of microelectronics in order to try to concentrate on applications in this area, in spite of the scanty interest displayed in Argentina in these generic technologies, except as mere users.

The main horizontal policy measures for the public sector are designed to increase the available funds, to bring about changes in the management of the respective bodies, and to change the manner of allocating funds for research by introducing competitive mechanisms.

The national budget for 1998 provided for a $12.6 \%$ increase in credit for public science and technology bodies (to 881 million pesos). This increase benefited in particular the National Water and Environment Institute (INA), INTA, INTI, the Argentine Geological and Mining Service (SEGEMAR) and CONICET.

At the same time, all bodies are required to formulate strategic plans in which they must clearly identify their institutional priorities, objectives, indicators of results and impacts, and self-appraisal mechanisms. It is proposed in the Plan that bodies which have formulated Strategic Plans and Proposals for Change in accordance with the guidelines of the Multi-Year National Plan and which are subject to the 
process of external appraisal to be carried out in the period 1998-2000 should be allowed more flexible conditions of management than those currently applied, including, among other things, the possibility of incorporating staff incentives based on the achievement of goals and results. Such changes are indispensable in order to establish greater links between the science and technology bodies and their users and to encourage their scientific staff to participate in technological tasks.

What is sought is to set in motion a significant process of restructuring of the public bodies in this field, whose performance has been very uneven and which, in general, lack goals and objectives defined as a function of the new context in which the Argentine economy and society are operating. Although it is obviously too early to pass judgement on a process which has only just been begun, both the complex past history of the bodies and the budgetary difficulties under which they have to operate, as well as the unequal levels of political will that seem to exist in GACTEC, shed doubts on the possibility of success in such a complicated process.

It is important to acknowledge, however, that INTI -one of the bodies whose functioning and organization we questioned in a detailed earlier study (Chudnovsky and López, 1995)- seems to have begun to overcome some of its past shortcomings by defining its action in the new context better, changing the generational profile of its staff, and strengthening both its horizontal activities and the linkages of the sectoral centres with users. Likewise, the National Commission on Spatial Organization (CONAE) now has a strategic plan which clearly defines its goals and tasks, and it has been one of the few public bodies which has effectively carried out auditing and evaluation activities.

Together with the launching of this reform process in the public science and technology bodies, part of the funds available to the Agency will be allocated to research projects put forward by these bodies (and non-profit-making foundations) through competitive mechanisms.

This means that, in addition to the funds they receive from the national budget, these bodies will be able to gain access to extra resources if the research projects they present are favourably evaluated in terms of their quality (judgement by their peers) and appropriateness (impact on economic and social development and on the educational sector, and conformity with the priorities laid down in the Plan). ${ }^{13}$ As the projects subsidized by the Agency also have to be co-financed by their executing bodies, by the private sector and by the provinces, it is essential that the extra funds should be allocated on a competitive basis and should back up the effects of public financing.

Although they are not very significant compared with the national public sector budget, which, as we already noted, amounts to 881 million pesos, the funds that FONCYT will have at its disposal as from 1998 are by no means negligible. It will have a budget of 36 million pesos, which, with the additional resources provided by the bodies executing the projects, will increase to 44.5 million pesos. It is proposed that FONCYT should allocate $75 \%$ of its budget $^{14}$ in line with the priorities laid down in the Plan, with the remainder being allocated to research projects in the other disciplines or subject areas.

With the aim of furthering the linkages which are of central importance in the NIS approach, the Plan provides that FONCYT will give priority to projects tending to form research networks, presented jointly by researchers from a given region, researchers from different regions of the country, or in conjunction with institutions of other countries under the various international cooperation agreements.

The introduction of competitive mechanisms for the allocation of public funds for research is undoubtedly a major change in the rules and places a big responsibility on the Agency, whose learning process is only just beginning and whose decisions will affect vested interests within the scientific community.

\section{Measures directed towards the private sector}

As well as promoting greater participation by enterprises in the research and development projects financed by FONCYT, FONTAR will continue promoting the existing credits, subject to compulsory repay-

\footnotetext{
${ }^{13}$ It is these resource allocation criteria which have given rise to most resistance and heavy criticism of the Plan among important segments of the scientific community (such as the Forum of Argentine Scientific Societies), which would obviously prefer to continue with the practices of the past in CONICET, since these largely benefit their members.

14 In turn, this $75 \%$ will be distributed as follows: $25 \%$ for projects on priority matters in the areas of health, education and the environment; $25 \%$ for projects in the food and agriculture, industrial and mining sectors, and $25 \%$ for projects reflecting priorities agreed upon with the provinces.
} 
ment, granted to enterprises through the Banco de la Nación Argentina and the other financial instruments at its disposal. ${ }^{15}$ At the same time, its performance will be strengthened with the launching of a programme of technological advisers for SMEs and a fiscal credit mechanism for promoting greater efforts in technological activities by private enterprise.

Although the unification of the various financial instruments within FONTAR is a sensible decision, in view of the experience of recent years it is hard to be optimistic about the impact this can have on the technological modernization process of the SMEs.

Of the various instruments provided for in Law No. 23877 for the promotion of technological innovation, it has only been possible to implement -and even then in quite an erratic manner- the credits for R\&D projects presented by entrepreneurs or "technological linkage units". ${ }^{16}$ These are credits at subsidized interest rates which are granted directly by the Science and Technology Department and require collateral to guarantee their repayment. Between 1993 and 1997, 25 credits were granted in the country as a whole for a total of 10.3 million pesos, with a total investment of 16.3 million pesos. The granting of these credits has been displaying a downward trend, going down from 13 in 1993 to 8 in 1996 and only one in 1997. Apart from the problems that have arisen in obtaining the necessary funds, a high proportion $(45 \%)$ of these credits have proved impossible to collect.

The compulsory repayment credits granted by the Banco de la Nación Argentina from its own funds and those of the Inter-American Development Bank are intended for relatively simple, low-risk technological modernization projects. Their maximum amount is US\$2 million, the interest rate is variable,

\footnotetext{
15 Among these are subsidies of up to 100000 pesos for projects involving high technical risk presented by SMEs, which must co-finance at least $50 \%$ of the total cost of the projects.

16 The idea of "technological linkage units" (TLUs) is one of the innovations of Law No. 23877 , inspired in theory by the NIS approach. TLUs are defined as non-State bodies formed for the identification, selection and formulation of $R \& D$ projects, transmission of technology and technical assistance. They may or may not be related with a public body, and their juridical status may be that of a commercial company or a civil association. The Science and Technology Department explicitly authorizes the functioning of TLUs, which, in spite of their potential virtues as means of favouring interaction between the supply and demand of technology, have not played a very significant role in practice.
}

and real guarantees are required. From 1995 to the present 29 credits have been granted to small and medium-sized enterprises for a total of US\$17.7 million, for total investments of US\$48 million.

Although there is an upward trend in the granting of these credits, only a small number have been granted so far, for various reasons: the high level of indebtedness of the SMEs; the Banco de la Nación Argentina's requirement that real guarantees be given; the limited experience of this bank in granting loans other than those of a traditional nature intended for fixed investments and the priority given to repayment capacity in deciding whether to grant them or not, and the impossibility of financing working capital and granting loans to new companies.

The fact that this bank is the only financial institution which has become involved in loans of this type, in spite of its limited experience, is also symptomatic of a deeper fault in the Argentine financial system: its lack of interest in channelling funds to technological modernization and innovation projects. This is a crucial matter which should be addressed in future versions of the Plan and discussed from the angle of the NIS (see OECD, 1995).

In view of the limitations of an approach based exclusively on the supply of loans, as part of the preparation of the Plan the Industrial Institute of the "General Sarmiento" National University has made a diagnostic study of demand: that is to say, of the technological challenges faced by small and mediumsized industrial enterprises. As a function of this study, and in the light of similar schemes in the industrialized countries and the Programme for Rural Change of the Ministry of Agriculture, a Programme for Improving the Technological Capacity of SMEs has been proposed which seeks to facilitate the progressive development of the supply of technological services so that they can make an effective contribution to improving the competitiveness of the user firms and to promote greater linkages between those requiring technical services and the public and private suppliers of such services.

In the various meetings held with small and medium-sized enterprises it became clear that their demands were for access to qualified information on product and process technology, including mechanization, improvements in quality, and technical standards. They also require specialized assistance on the optimization of production processes, technologically more complex products, suitable materials, quality 
assurance, conversion of their firms, and new market and product niches. In short, they need assistance to improve their skills and also to satisfy certain specific training needs.

At the same time, the shortcomings in terms of information on the supply of services from public bodies, universities, enterprises and other institutions were highlighted. In the cases where SMEs made use of these suppliers it became evident that the services needed to be more flexible and better adapted to the special conditions of these kinds of enterprises. A demand thus arose for specialized services which not only diagnose the technological problems of the SMEs more effectively but also help them to find possible solutions.

Technological advisers form the hub of the Programme to Improve the Technological Capacity of SMEs, which we will therefore refer to as the Technological Advisers Programme. The role of the adviser is to enable the enterprise to evaluate its technical capacity, identify its needs and seek the solutions and options considered most useful. The adviser expands the range of material available for helping to take decisions and helps to set in motion the process of strengthening the firm's capabilities. The adviser's job is not to overcome these shortcomings but to help to overcome them.

The Technological Advisers Programme aims mainly to develop a technological advisory services market for the approximately 15000 Argentine industrial SMEs operating in tradeable goods sectors. Two types of advisory assistance are envisaged: institutional technological advisory assistance and individual technological advisory assistance. In the first case, an advisory assistance scheme will be established on the basis of internships by young graduates in engineering and other appropriate technological and scientific subjects. Their participation will be organized through private and/or public non-profitmaking institutions (such as the engineering faculties of universities) which will offer SMEs advisory support through interns stationed in each firm and supervised by experienced professionals.

In the second case, there will be individual advisers supporting and advising a small group of enterprises on a personal basis. Through chambers of industry and business associations or temporary associations of enterprises, groups consisting of a dozen or so SMEs will be formed which will be provided with an exclusive adviser through a collective pro- gramme of activities and needs. Each group will present a programme of work when FONTAR invites applications for advisory assistance.

The Technological Advisers Programme will be financed with funds made available under Law No. 23877 and administered by FONTAR (5.4 million pesos in 1998), with the contributions of the firms making use of the service, and with other funds available to the bodies that will provide the advisory services.

This programme is undoubtedly a good initiative which fits in well with the NIS approach and is inspired by some elements of the best international practices (Humphrey and Schmitz, 1996, and OECD, 1997).

In contrast with the many programmes existing in Argentina which are based on the supply of financing or non-financial services to individual firms, and which generally subsidize physical investments or working capital, the Technological Advisers Programme has been motivated by the demands of the production sector itself and is designed to link up public technological institutions and universities with groups of firms rather than individual firms. The subsidy that firms can obtain in order to help pay for the advisory services will enable the SMEs to bring highly-qualified engineers into their staff (often for the first time) and will help them to begin to appreciate the importance of their services.

At the same time, the Technological Advisers Programme offers employment opportunities for young engineers and facilitates contact with the realities of the production sector right from the start of their professional career. It will also give an opportunity to experienced professionals to establish closer links with the specific needs of the production sector, to supervise the work of the young graduates, and to enrich their own work in their institutions with firsthand information on what really takes place on the shop floor. The fact that the advisers do not merely visit the firms occasionally but actually participate systematically in the activities of the firms should make for smoother transmission and development of tacit know-how. At the same time, an essential mission of the advisers is to facilitate the access of the firms to the services of public sector science and technology institutions and, in turn, to cause the latter to take more account of the specific requirements of the production sector.

However, the difficulties that the initiation of this programme may involve must not be underesti- 
mated. Apart from the lack of experience of FONTAR and of the country as a whole in this type of policy instruments, enterprises may be reluctant to participate for various reasons: reluctance to work in groups, lack of confidence in the ability of the advisers and institutions to provide good service, difficulties in financing that part of the services which is not subsidized by the State, etc. Moreover, the universities and other institutions may not be sufficiently motivated to take on tasks they are not used to and which will not provide significant direct benefits, while the knowledge possessed by the young graduates may not be sufficient for the tasks involved and the SMEs may very soon feel disappointed. Furthermore, as proposed in the Plan, the Technological Advisers Programme should interact closely with the various other programmes already in operation for the SMEs, ${ }^{17}$ but this aspiration comes into conflict with an existing situation which is hard to change, marked by extensive dispersion of efforts and lack of coordination in this field.

While some of these initial obstacles may be overcome as the work proceeds and the Technological Advisers Programme may steadily gain experience and credibility, it is necessary to bear in mind some other types of problems that may occur in demand-led mechanisms for small and medium-sized enterprises. In an interesting study on the recent experience of the Chilean Production Development Corporation (CORFO) in putting into effect a scheme of this type, it is noted that the costs of gaining access to the development system may mean that a handful of enterprises may, by definition, have preferential access, although these firms are the most dynamic in their field and, in theory, have the least need of public support. Moreover, as what is involved are tacit activities subject to incomplete specifications and highly imperfect transferability, it is unlikely that the beneficiary firms will have much incentive -or even much possibility - to pass on their own experience to others, thus sharply reducing the externalities (Dini and Katz, 1997).

With regard to other policy instruments for incentivating both large and small domestic enterprises and subsidiaries of foreign companies to make research and development efforts with their own quali-

17 The corresponding part of the Plan lists 31 existing instruments directed towards the SMEs, of which 13 are closely linked with the Technological Advisers Programme. fied personnel or under contracts with research institutions, fiscal credit amounting to 20 million pesos has been provided for in the 1998 national budget. ${ }^{18}$

In order to try to obviate the abuses to which these types of incentives sometimes give rise, the fiscal credit certificates will be awarded by competition to the research and development projects submitted to the Agency. These certificates can be used by their holders to pay off future profits tax commitments, up to a percentage which goes down according to the size of the relevant annual tax commitment.

Inasmuch as they help to finance up to $50 \%$ of the cost of executing projects, these public funds will serve as an incentive for increased private expenditure on $R \& D$. Thus, it is estimated that this fiscal credit will generate an additional private sector contribution of some 30 million pesos.

With this fiscal credit, Argentina is placing itself on the same footing as many other countries -especially Brazil, for example- which use this instrument, accepted by the World Trade Organization, to encourage the private sector to make research and development efforts. Unlike the financial incentives which are designed primarily to help SMEs, this fiscal credit will not only be useful for those firms which have tax obligations but will undoubtedly also be of interest to large enterprises in general.

According to the available estimates, private sector expenditure on R\&D in 1996 came to 369 million pesos, so that the impact the fiscal credit may have on private sector behaviour is quite small and will probably only benefit large companies which already engage in activities of this type. At all events, this credit can become an incentive for firms to do more in this area -as is shown by the recent experience of Brazil in the implementation of Law No. 8661/93- and thus have multiplier effects.

While not denying the importance of a stable macro economy and high growth rates, and while acknowledging the value of the financial and fiscal incentives, the research and development projects financed by FONCYT, and the Programme to Improve the Technological Capacity of SMEs, there can be no doubt that this context and these instruments are nothing like big enough to bring about a substantial change in the behaviour of large or small firms in technological matters.

\footnotetext{
${ }^{18}$ In reality, this represents the fulfillment of an outstanding task: adoption of the regulations for the fiscal credit provided for in article 9 of Law No. 23877.
} 
In order to cope with the change in the rules of the game involved in competing in economies which are more open to international trade and to the entry of new competitors, the surviving enterprises have generally redoubled their technological efforts to gain efficiency and secure improvements in productivity and quality. However, this process has been very heterogeneous as regards the activities involved, the size of the firms, and their geographical location.

While most of the SMEs which have survived have done so by trying to improve their productivity and quality, a considerable number of firms (especially big companies) have not only invested in imported capital goods but have also made use of licenses or technical assistance from abroad or have been bought out by foreign investors. At the same time, these firms have presumably also made efforts to absorb the technologies received from the exterior and to adapt them and make some innovations in products and processes. However, the information available for analysing this complex process of "creative destruction" is very fragmentary and only provides evidence of this phenomenon in some foreignowned firms and large domestic enterprises.

At the beginning of the 1990s, a group of 39 subsidiaries of transnational corporations operating in various industrial sectors registered average $R \& D$ expenditure equivalent to around $1 \%$ of their sales (Kosacoff and Bezchinsky, 1993), which is rather higher than the level estimated for the Argentine manufacturing sector as a whole. Our studies on FDI have revealed that endogenous efforts in the subsidiaries are concentrated on staff training and improvements in quality and productivity. Of the privatized enterprises, only one of the telephone companies maintains a research and development laboratory, not linked to that of the parent company, for operational reasons. In the manufacturing firms, the biggest efforts in this field (generally equivalent to less than $1 \%$ of sales) were found in the manufacturers of telecommunications equipment and some firms in the food industry engaged in the export of staple goods (Chudnovsky, Porta, López and Chidiak, 1996).

Likewise, significant efforts to improve the technological training of suppliers are only to be found in the motor industry, where in many cases they have involved the acquisition of local automobile component firms by foreign companies. The technological externalities generated by the presence of transnational corporations appear to be only weak, in view of the small scale of innovative activities in the subsidiaries and the scanty technological linkages of these firms with local suppliers or research institutes.

In the pharmaceutical sector, significant research and development efforts have been made by some local firms. In other areas of activity, the expenditure of these firms is similar to or less than that of the subsidiaries of transnational corporations. In the few economic conglomerates which engage in activities of this type, their expenditure is equivalent to less than $1 \%$ of their sales. As long as strategic alliances with international corporations continue to be frequent in these conglomerates it is doubtful that there will be many agreements giving priority to technological innovation activities. However, this is a matter which calls for greater study.

The fact that the private sector spends little on $R \& D$ is partly a consequence of the type of branches in which production investment is concentrated in Argentina. These are generally activities which are based on natural resources or in which economies of scale are important, and in which R\&D expenditure is not very high at the international level either. The same is true, at the international level, of the activities in which the privatization operations have been concentrated (water, electricity, gas, petroleum). Only the telecommunications sector makes intensive use of $\mathrm{R} \& \mathrm{D}$, but not in Argentina.

However, the backward or forward linkages of the sectors in which investments have been concentrated could give rise to activities making intensive use of knowledge; moreover, some segments of the specialized machinery and equipment industry could be revitalized, along with some activities based on the country's stock of scientific personnel.

It is possible that domestic and foreign enterprises may slowly and spontaneously increase their innovative activities and even invest in knowledgeintensive branches. In this case, it could be argued that, in addition to a growing macro economy and the horizontal instruments mentioned earlier, laissez-faire would be the most suitable policy for the private sector.

If it is considered, however, that this process should be deliberately accelerated and that such activities should be promoted through specific policies, it does not seem possible to ignore the sectoral context, for that is precisely where the weaknesses of the new science and technology policy make themselves felt. Only in the case of mining, where there is a well-defined sectoral policy, and food and agricul- 
tural production, where an effort to define policy lines is beginning to be made, is the technological variable being explicitly incorporated in sectoral dynamics.

In the rest of manufacturing, in contrast, the technology variable has been absent from the decisions that the national government has taken with regard to schemes to permit the adaptation of various industrial sectors within MERCOSUR and the treatment given to the local machinery and equipment industry. ${ }^{19}$ In the scheme for the motor industry, the transnational corporations and/or their local licensees have been allowed to act in matters of technology according to their own interests, without trying to obtain too many externalities with regard to the de- velopment of suppliers, environmental management, staff training and links with technological institutes. ${ }^{20}$

As we noted earlier, in sectors which are of crucial importance for the NIS such as health, education and the environment the question of science and technology is mentioned in rhetorical rather than effective terms in the policies indicated in the Plan.

While the government's efforts to promote traditional activities based on natural resources -such as mining, agroindustry, gas and petroleum- are clear for all to see, there is a conspicuous absence of initiatives designed to promote knowledge-intensive activities (except those outlined in the Plan in the area of biotechnology) in the sectors producing goods and services.

\section{IV}

\section{Final observations}

In a stable and growing economy, the reorganization of the science and technology sector, tardy but nevertheless finally under way, and the concepts, diagnoses and horizontal policies set forth in the Plan are undoubtedly positive elements.

Inasmuch as it centers much of public policy on the promotion of interactions between supply and demand, between the public and private sectors, between science and technology institutions and users, between inputs from abroad and local efforts, and between provincial activities and national priorities, the Plan is clearly inspired by the NIS approach.

By increasing financing and at the same time beginning to change the rules for allocating public

\footnotetext{
${ }^{19}$ In order to favour the investment process and the technological modernization of users, in 1993 it was decided to apply a zero tariff to imported capital goods and to compensate local manufacturers through a subsidy to purchasers of their equipment equal to the value of the tariff forgone. Apart from the delay in granting the relevant subsidy, which aggravated still further this sector's difficulties in adapting to the new rules of the game, the question of the technological development potential of the local capital goods industry was totally absent from government policy. As from 1995 the tariffs on the capital goods sector were raised within the convergence operations agreed in MERCOSUR, but there continues to be no specific policy for such an important sector in the NIS.
}

resources to research (establishment of the Agency, with competitive allocation of funds and evaluation by peers); by promoting strategic plans and appraisal mechanisms in the public science and technology bodies; and by trying to establish some priorities in the allocation of funds, such public policy fosters institutional changes which can invigorate the anaemic scientific and technological complex and begin to reduce its most obvious systemic flaws.

Likewise, by introducing fiscal credit for R\&D and trying to link up the financial incentives more effectively with the prevailing technological modernization process, and above all by launching the Technological Advisers Programme, the Plan seeks to give better attention to the requirements of the SMEs and to begin to reverse the reluctance of enterprises to make investments in technological innovation to complement the massive inflow of inputs from abroad.

Unfortunately, these horizontal policies are only matched by adequate sectoral efforts in the case of

\footnotetext{
${ }^{20}$ In 1994 the Ministry of Industry launched an interesting Supplier Development Programme, which, however, for reasons that are worth investigating, does not seem to have been a success.
} 
the mining sector and, possibly, food and agricultural production. They are far from being adequately complemented by sectoral efforts in the rest of manufacturing, health, education and the environment.

This brings us to the most obvious negative aspects that militate against the objectives and policies of the Plan. The flaws which exist in Argentina with regard to the ability of the financial system to finance long-term investments in intangible assets, the inadequate capability of the educational system to link up with the needs of the production sector, and the limited capability of the scientific institutions to interact with the educational and production systems are extremely deep-seated. These flaws are mentioned in the Plan, but they are far from receiving the attention needed in order to begin to correct them.

Although GACTEC seems to be a good institutional solution for tackling the cross-sectional problems displayed by science and technology policy, it is still far from functioning as a means of coordinating science and technology policy with sectoral policies, and still further from designing a long-term vision to guide investment efforts in tangible and intangible assets and in the training of human resources in the country. For this purpose, it would be necessary, at the very least, for the level of commitment to scientific and technological problems displayed in the current actions of the Department of Science and Technology to be repeated in the other ministries and departments involved.

However, the public discussion of the Plan, in which a thousand or more persons have participated in various workshops and seminars, has enriched its final version, and it may be expected that in the successive annual reviews it will be further perfected and some of its shortcomings will begin to be corrected. Nevertheless, time is obviously needed in order for the effects of the changes in the rules and proposed policies to make themselves felt.

At all events, caution is called for in trying to predict the effect that the present policies may have in terms of reversing the crisis that affects the public sector in this field and changing the patterns of behaviour of the private sector.

In Argentina, the long and frustrating history of science and technology policies registers more failures than successes, whereas the laissez-faire approach of the 1990s has been partly successful and is supported by most of local and foreign big business. Both of these are weighty factors that militate against the success of the initiatives under way. At the same time, in spite of its very interesting proposals, the NIS approach displays profound normative and conceptual ambiguities which limit its practical application.

In these circumstances, the merely incipient level of commitment to the science and technology issue in the national cabinet reflects long-standing problems in the country. In civil society, and particularly in the productive sectors, there is little awareness of how important the contribution of science and technology may be for the country's economic and social development. In the big domestic and foreign firms, much more importance is attached to inputs from abroad than to endogenous efforts that go beyond the need to ensure the proper management of production facilities and the quality of the goods produced. Likewise, society and the production sectors set little store by the activities of Argentine scientists and technologists. Nor indeed have the latter made much of an effort in general to link up their research projects with the far-reaching and changing needs of the country.

In spite of the structural limits facing the present policies, the diagnosis of the Argentine situation in this field will be more accurate and the possibilities of improving and broadening the corresponding public policies will be increased if, through future research, a number of questions can begin to be answered:

First, it is necessary to follow up and analyse with close attention the way that the initiatives already launched are being put into practice, especially with regard to the reorganization of the science and technology bodies, the management of the competitive funds administered by FONCYT, fiscal credit, and the FONTAR Technological Advisers Programme, and the policies in the fields of mining and food and agricultural production.

Second, the results of the survey on the technological conduct of Argentine industrial companies will make it possible to analyse the size and nature of the innovation efforts of the private sector (both small and medium-sized enterprises and big domestic and foreign firms) and to determine to what extent the various inputs from abroad complement local efforts in various branches of manufacturing. It will also be important to study the kind of interactions firms have been establishing in the country with the various local and foreign agents and institutions. 
Third, the potential for the development of knowledge-intensive activities in Argentina is worth studying in depth, together with the feasibility of applying policies like those followed in other countries to promote this kind of activities (enterprise brooders, innovation parks, etc.).

Fourth, it is necessary to examine the faults in the Argentine financial system and the possibility of correcting them in order to promote greater availability of financing for intangible activities.
Lastly, the problems faced by higher and technical education and its possibilities of training the human resources needed by the NIS represent a vital issue which has not yet been addressed in the necessary depth. The training of human resources for an economy increasingly based on knowledge calls for detailed studies not only of supply but also of demand, as a function of medium- and long-term scenarios for the country's economic and social development.

(Original: Spanish)

\section{Bibliography}

Adler, E. (1987): The power of ideology. The quest for technological autonomy in Argentina and Brazil, Berkeley, California, University of California Press. Argentina, GACTEC (Gabinete Científico-Tecnológico) (1997): Plan nacional plurianual de ciencia y tecnología, 1998-2000, Buenos Aires.

Argentina, Ministerio de Economía y Obras y Servicios Públicos, Secretaría de Política Económica (1997): Informe económico. Segundo trimestre de 1997, year 6, No. 22, Buenos Aires.

Carlsson, B. (ed.) (1995): Technological Systems and Economic Performance: The Case of Factory Automation, Dordrecht, Netherlands, Kluwer Academic Publishers.

CEP (Centro de Estudios para la Producción) (1997): Notas de la economía real, No. 4, Buenos Aires, Ministerio de Economía y Obras y Servicios Públicos, Secretaría de Industria, Comercio y Minería, October.

Chudnovsky, D. and A. López (1995): Política tecnológica en la Argentina ¿Hay algo más que laissez. faire?, Documentos de trabajo, No. 20, Buenos Aires, Centro de Investigaciones para la Transformación (CENIT).

Chudnovsky D., F. Porta, A. López and M. Chidiak (1996): Los límites de la apertura, Buenos Aires, CENIT/Alianza Editorial.

Dahlman, C. and R. Nelson (1993): Social absorption capability, national innovation systems and economic development, Maastricht, Netherlands, United Nations University, Institute for New Technologies (INTECH), mimeo.

David, P. and D. Foray (1995): Accessing and expanding the science and technology knowledge base, STI Review. Science and Technology Industry, No. 16, Paris, Organization for Economic Cooperation and Development (OECD).

Dini, M. and J. Katz (1997): Nuevas formas de encarar las políticas tecnológicas en América Latina, REDES.
Revista de Estudios Sociales de la Ciencia, vol. 4, No. 10, Buenos Aires, Universidad Nacional de Quilmes, Centro de Estudios e Investigaciones.

Edquist, C. (ed.) (1997): Systems of Innovation: Technologies, Institutions and Organizations, London, Pinter Publishers.

Edquist, C. (1997): Systems of innovation approaches: Their emergence and characteristics, in C. Edquist (ed.), Systems of Innovation: Technologies, Institutions and Organizations, London, Pinter Publishers.

Freeman, C. (1988): Japan: A new national system of innovation?, in G. Dosi, C. Freeman, R. Nelson, G. Silverberg and L. Soete (eds.), Technical Change and Economic Theory, London, Pinter Publishers.

- (1995): The national system of innovation in historical perspective, Cambridge Journal of Economics, vol. 19, No. 1, London, Cambridge Political Economy Society.

Humphrey, J. and H. Schmitz (1996): The triple C approach to local industrial policy, World Development, vol. 24, No. 12, Oxford, U. K., Pergamon Press.

Kosacoff, B. and G. Bezchinsky (1993): De la sustitución de importaciones a la globalización. Las empresas transnacionales en la industria argentina, in B. Kosacoff and others, El desafío de la competitividad. La industria argentina en transición, Buenos Aires, Economic Commission for Latin America and the Caribbean (ECLAC)/Alianza Editorial.

Lall, S. (1992): Technological capabilities and industrialization, World Development, vol. 20, No. 2, Oxford, U. K., Pergamon Press.

(1995): Governments and industrialization, paper presented at the international seminar on Productivity, Technical Change and National Innovation Systems in Latin America, Marbella, Chile, ECLAC, mimeo.

Lundvall, B. (1992): National Systems of Innovation. Towards a Theory of Innovation and Interactive Learning, London, Pinter Publishers. 
Mowery, D. (1993): Inward technology transfer and competitiveness: The role of national innovation systems, Berkeley, California, University of California, Haas School of Business, mimeo.

Mytelka, L. (1992): Strategic partnering: Some lessons for Latin America, Paris, Université de Paris, mimeo.

(1996): Competition, innovation and competitiveness: A framework for analysis, in L. Mytelka (ed.), Competition, Innovation and Competitiveness in Developing Countries, Paris, OECD Development Centre.

Nelson, R. (ed.) (1993): National Innovation Systems. A Comparative Analysis, New York, Oxford University Press.

OECD (1992): Technology and the Economy. The Key Relationships, Paris.
(1995): National Systems for Financing Innovation, Paris.

(1996a): OECD Programme on National Innovation Systems. Synthesis report, No. 4, Paris, mimeo.

- (1996b): Science, Technology and Industry Outlook 1996, Paris.

- (1997): Diffusing Technology to Industry: Government Policies and Programmes, Paris.

Williamson, J. (1990): Latin American Adjustment. How Much has Happened?, Washington, D. C., Institute for International Economics (IIE).

(1997): The Washington Consensus revisited, in L. Emmerij (ed.), Economic and Social Development into the XXI Century, Washington, D. C., InterAmerican Development Bank (IDB)/The Johns Hopkins University Press. 